\title{
DØ CRYO CC PRESSURE VESSEL HEAD TO CYLINDER WELD TEST \\ RESULTS
}

DØ ENGINEERING NOTE

3740.214-EN-303

JOHN URBIN

17 MAR 91

REVIEWED: C, H. Heeke DATE: $3 / 2,2 / 5$, 


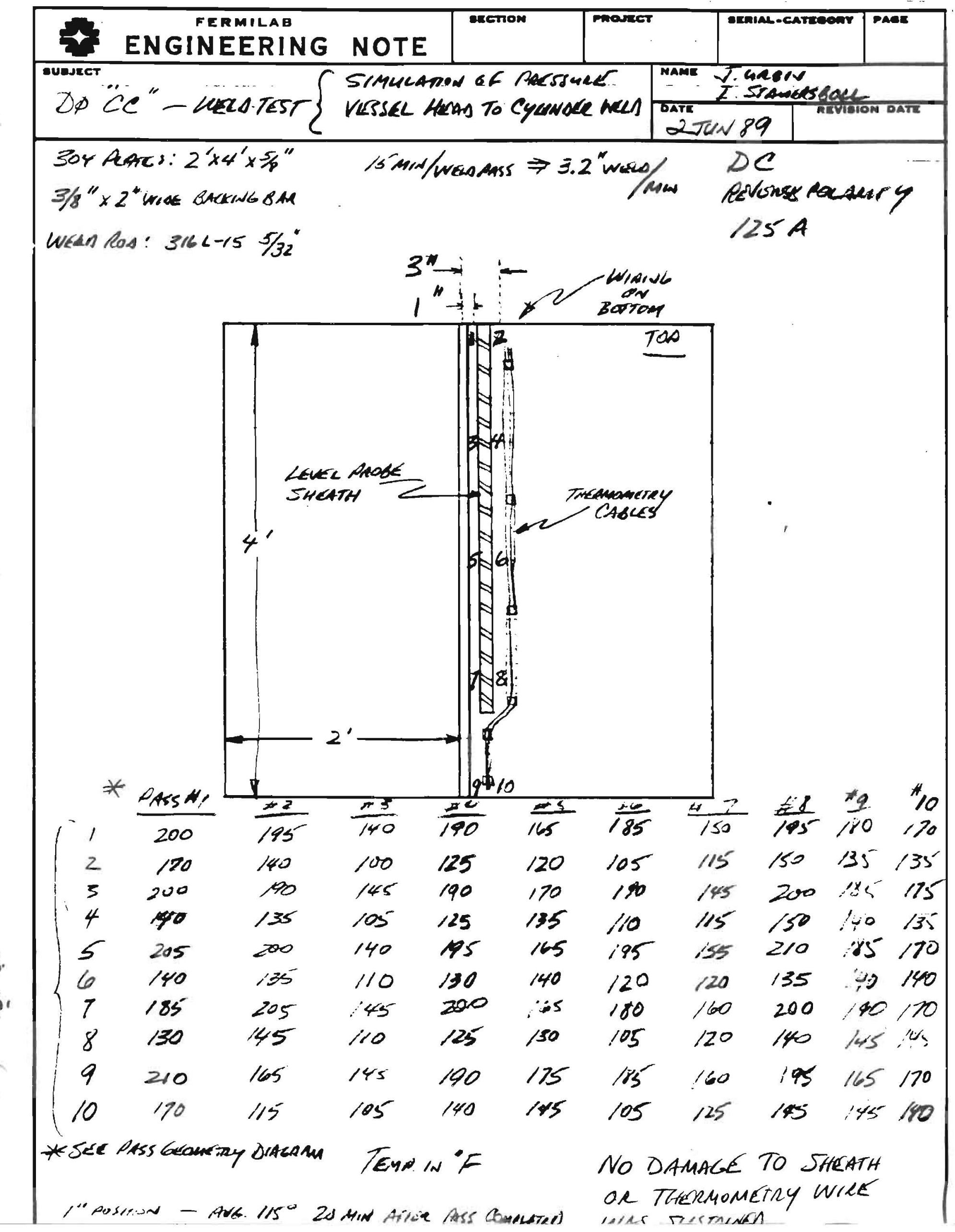




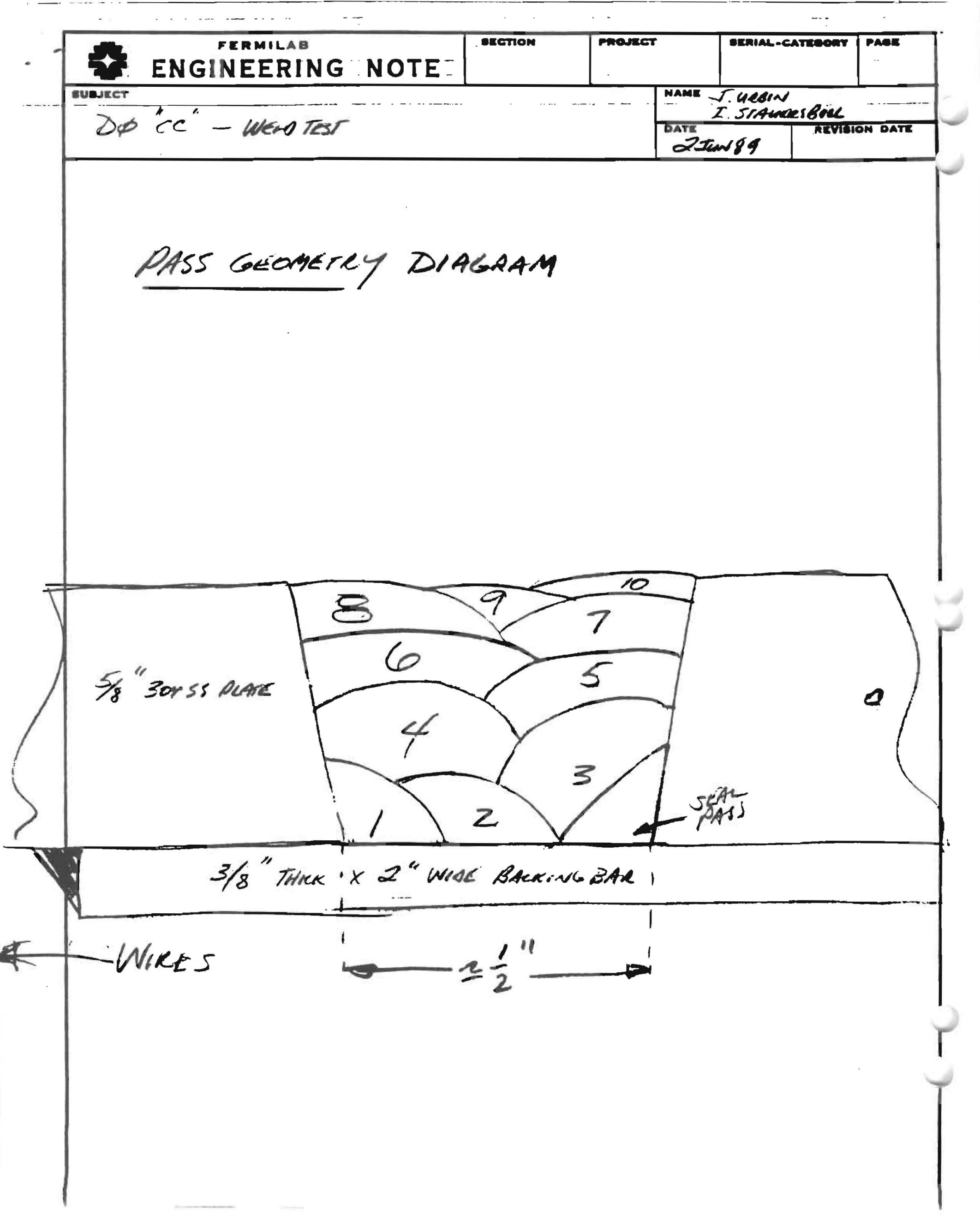




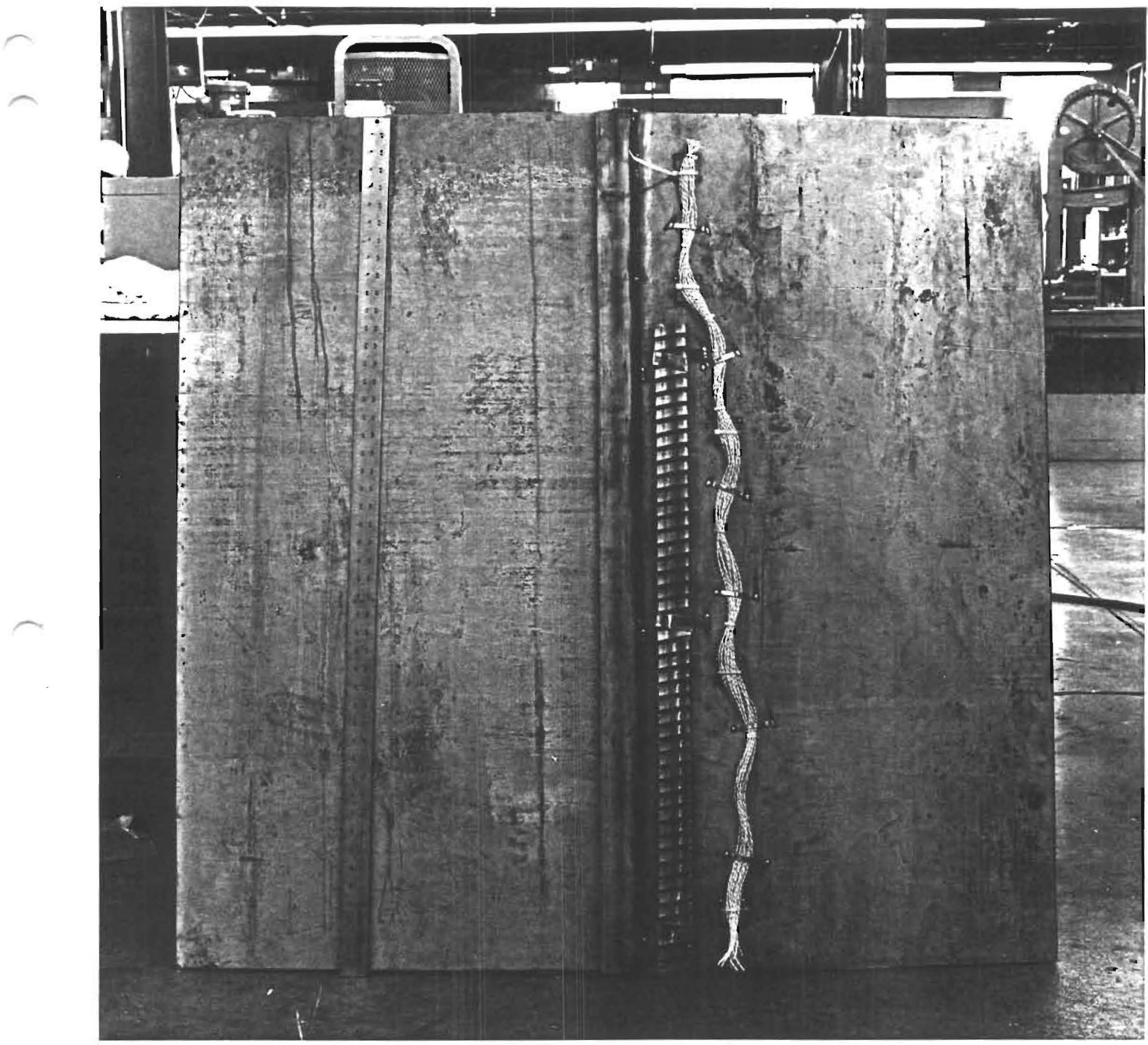




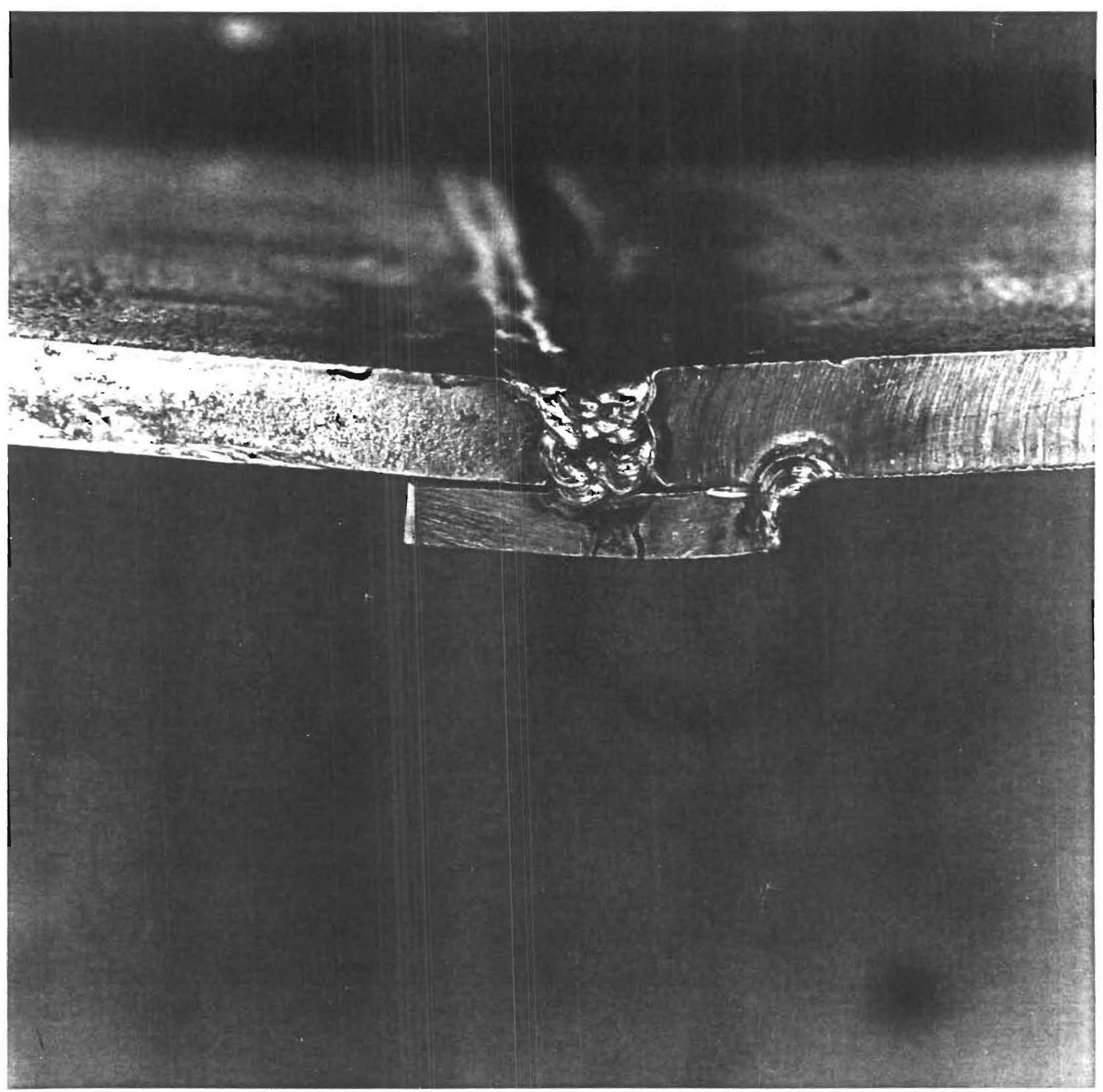

